and the corresponding gene flow ${ }^{10}$, the nuclear DNA data nonetheless suggest that a possible male-mediated gene flow between colonies is insufficient to prevent a genetic substructuring even of closely neighbouring colonies.

The consequences for conservation management are obvious. The preprogrammed female reproductive behaviour makes it unlikely that the loss of a breeding habitat (because of human building operations, for example) can be compensated for by emigration to other colonies; that is, the loss of nesting sites is accompanied by the loss of specific genotypes. Thus, to preserve the genetic diversity of the Caretta metapopulation one needs to preserve individual nesting sites (attempts to transfer freshly deposited eggs between sites - based on the hope that hatchlings would accept a new hatching site as natal - are controversial). In addition, the described haplotypes may serve as genetic tags to identify the colony membership of individuals offshore or illegally commercialized, and also to complete our knowledge of sea turtle migratory behaviour offshore ${ }^{11}$.

\section{Werner Schroth \\ Bruno Streit}

\section{Bernd Schierwater*}

Abteilung Ökologie \& Evolution,

J. W. Goethe-Universität,

D-60054 Frankfurt,

Germany

*and Department of Biology,

Yale University, New Haven,

Conneticut 06520-8114, USA

e-mail: Schierwater@zoology.unifrankfurt.de

1. Carr, A. F. BioScience 14, 49-52 (1964).

2. Lohmann, K. J. \& Lohmann, C. M. F. Nature 380, 59-61 (1996).

3. Bowen, B. W. \& Avise, J. C. in Conservation Genetics: Case Histories from Nature (eds Avise, J. C. \& Hamrick, J.) 190-237 (Chapman and Hall, New York, 1995).

4. Allard, M. W. et al. Copeia 1994, 34-41 (1994).

5. Bowen, B. W. BioScience 45, 528-534 (1995)

6. Williams, J. G. K. et al. Nucleic Acids Res. 18, 6531-6535 (1990)

7. Hadrys, H., Ballick, M. \& Schierwater, B. Mol. Ecol. 1. 55-63 (1992).

8. Laurent, L. WWF Report (International Mediterranean Program RAC/SPA, Greenpeace Mediterranean Sea Project, 1994)

9. Bowen, B. W. et al. Conserv. Biol. 7, 834-844 (1993)

10. Karl, S. A., Bowen, B. W. \& Avise, J. C. Genetics 131 163-173 (1992).

11. Schierwater, B. \& Ender, A. Nucleic Acids Res. 21 4647-4648 (1993).

12. Excoffier, L., Smouse, P. E. \& Quattro, J. M. Genetics 131, 479-491 (1992).

\section{Erratum}

In the Scientific Correspondence “Competition for royalty in bees” by R. F. A. Moritz, Per Kryger and Mike H. Allsopp (Nature 384, 31; 1996), the $y$-axis labels of Fig. 2, showing the mean offspring frequencies of various patrilines of a honeybee colony, were printed incorrectly. In the top panel the scale should have read ' $0-20 \%$ ', not ' $0-2 \%$ ' as printed, and in the middle and bottom panels '0-80\%' rather than ' $0-8 \%$ '.

\title{
Human effect on global climate?
}

SIR - The recent pattern-correlation analysis of Santer et al. ${ }^{1}$ has drawn considerable attention: Nicholls ${ }^{2}$, for example, stated that it represents the "clearest evidence yet that humans may have affected global climate". This conclusion is based on the increasing similarity of the vertical temperature pattern in freeatmosphere and global-climate models incorporating combinations of carbon dioxide, sulphate aerosols and stratospheric ozone concentrations as measured by a 'centred' correlation statistic, $R(t)$.

Santer et al. ${ }^{1}$ found significant increases in $R(t)$ in the $850-50-\mathrm{hPa}$ region of the atmosphere over the period of their study (1963-87) for each of the climate model/atmospheric constituent combinations they analysed (with the exception of a sulphate-only model). We agree with Santer et $a l^{1}{ }^{1}$ that this result stems largely from the pattern of stratospheric and upper tropospheric cooling and a hemispheric asymmetry in the lower and midtroposphere. But we believe that the reported increases in $R(t)$ are almost totally caused by the higher-altitude temperature changes, and that in the lower levels the results are only a reflection of the time period chosen.

For example, using the carbon dioxide + sulphate model results from Taylor and Penner ${ }^{3}$ (Fig. 2 of ref. 1), we can compare the explained variance (obtained by squaring $R(t)$ ) at the end of the record (1987) between the $850-50-\mathrm{hPa}$ layer (troposphere + stratosphere) to that for the $850-500-\mathrm{hPa}$ layer (lower troposphere only). The values are $64 \%$ and $5 \%$, respectively. Thus $92 \%$ of the explained variance results from the addition of data above $500 \mathrm{hPa}$. This result is typical for the models used in this study (with the exception of the sulphate-only model). Further, the calculation of $R(t)$, using four levels above $500 \mathrm{hPa}$ and only two beneath, assures heavy dependence upon the upper troposphere and stratosphere.

The factor that largely constitutes the hemispheric asymmetry is the warming of the mid-troposphere in the Southern Hemisphere, which appears both in the $\mathrm{CO}_{2}+$ sulphate models (Fig. $1 c, e, g-i$ of ref. 1 ) and in the observations, where it is concentrated between 850 and $300 \mathrm{hPa}, 30$ to $60^{\circ} \mathrm{S}$ (Fig. $1 j$ of ref. 1 ). The observed data in ref. 1 are from the record of Oort and $\mathrm{Liu}^{4}$. This record extends to 1989 (although annual data to only 1987 are used by Santer et $a .^{1}{ }^{1}$ ). The radiosonde record of Angell $^{5}$ is longer (1958-95). Over the period of concurrency between refs 1 and 5, the correlation coefficient between annual anomaly values is 0.94 in the Northern Hemisphere and 0.92 in the Southern Hemisphere.

When we examine the period of record used by Santer et al. in the context of the longer period available from ref. 5, we find that in the region with the most significant warming $\left(30-60^{\circ} \mathrm{S}, 850-300 \mathrm{hPa}\right)$ the increase is largely an artefact of the time period chosen ( $a$ in our figure). Although there is a statistically significant warming in the period from 1963-87, there is no significant change in the entire (1958-95) record. This has considerable bearing on the portion of $R(t)$ in ref. 1 that emanates from Southern Hemisphere mid-tropospheric warming. This result cannot be an artefact of the data, as precisely the same set of stations was used by Angell during the entire record.

Additionally, as $R(t)$ is a pattern-matching statistic, the increases in the tropospheric contribution to it are strongly dependent on the hemispheric temperature differences. The climate models predict that the Southern (sulphate-free) Hemisphere should warm relative to the Northern (sulphate-laden) Hemisphere, and for the period of record used in this study (1963-87) the observations agree. However, a close examination of upper-air temperature records again exposes this agreement as being fortuitous.

Using data from ref. 5, we present the 850-300-hPa hemispheric temperature differences ( $b$ in our figure). These data are highly correlated with the tropospheric $R(t)$ values calculated in ref. 1 from the $\mathrm{CO}_{2}+$ sulphate model in ref. $3(r=0.80)$.
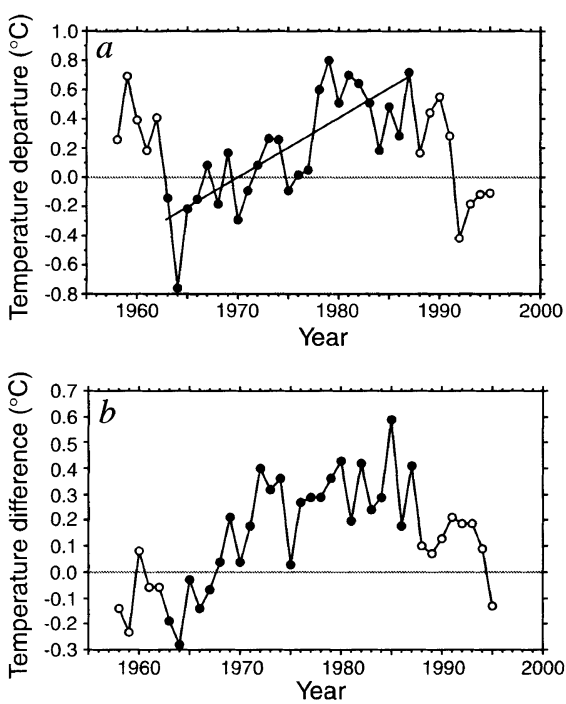

a, The Angell ${ }^{5}$ temperature departure $\left({ }^{\circ} \mathrm{C}\right)$ his tory for 1958-95 for the 850-300-hPa layer between 30 and $60^{\circ} \mathrm{S}$ latitudes. Solid circles, years studied in ref. 1 . There is a statistically significant $(P<0.0001)$ increase during 196387 , whereas the overall record exhibits no significant trend. $b$, Annual temperature difference $\left({ }^{\circ} \mathrm{C}\right)$ between Southern and Northern hemispheres in the 850-300-hPa layer, from ref. 5. There is a statistically significant $(P<$ $0.05)$ downward trend in this data since 1972. Solid circles, period studied by Santer et al. 